\title{
Survey and molecular characterization of Nomuraea rileyi isolates
}

K. SWETHA* AND K. MANJULA

Department of Entomology, S.V. Agricultural College, TIRUPATI (A.P.) INDIA

\begin{tabular}{ll} 
ARITCLE INFO \\
\hline Received & $: 30.05 .2014$ \\
Accepted & $: 23.09 .2014$
\end{tabular}

KEY WORDS :

Nomuraea rileyi, Molecular characterization, RAPD-PCR, Primers, Polymorphism

\begin{abstract}
After conducting a roving survey in Chittoor district for the natural occurrence of Nomuraea rileyi, a few fungal infected and died (mummified) cadavers of Spodoptera litura and Bombyx mori were found and collected. With microscopic studies, the fungus was identified as Nomuraea rileyi and Beauveria bassiana. The molecular characterization of 7 isolates of $N$.rileyi was done by RAPD-PCR for studying the genetic variability/similarity. RAPD banding profile with 12 different random primers viz., 3 primers from OPD, 3 primers from OPY, 2 primers from OPM, 2 primers from OPA, 1 primer from OPC and 1 primer from OPW (Operon technology) showed 88.6 per cent polymorphism as all the bands obtained were polymorphic with size ranging from $100 \mathrm{bp}$ to $3000 \mathrm{bp}$. Jaccards similarity co-efficients between the N.rileyi isolates showed 97.50 per cent genetic variation between isolates of Tirupati and V.Kota-1. While the isolates V.Kota-2 and Madanapalli were found to be genetically similar as 70.3 per cent similarity was observed between the isolates. In the resulted dendrogram V. Kota-2 and Madanapalli isolates formed one group and V. Kota-2 and Kanumakupalli another group and remaining isolates did not form any group.
\end{abstract}

How to view point the article : Swetha, K. and Manjula, K. (2014). Survey and molecular characterization of Nomuraea rileyi isolates. Internat. J. Plant Protec., 7(2) : 482-485. 